\title{
Research on the Corresponding Relationship between Tool Wear Position and Chip Type in Cutting Process
}

\author{
Li Zhe, Li Yongfu, Zhai Quanpeng, Zheng Minli and Li Long \\ School of Mechanical and Power Engineering, Harbin University of Science and \\ Technology, Harbin 150080, China \\ lizhe-088@163.com
}

\begin{abstract}
In this paper, as workpiece ICrl8Ni9Ti for researching foundation, under turning experiments, with the high speed camera, piezoelectric dynamometer and FEM thermal imager, get relevant data from the cutting process, analyze the effect law of geometry shape and chip type from the cutting force, cutting heat, tool wear and breakage as well, in the removal process. By analyzing and summarizing the tool wear position, study the formation, curl, liquidity of chip and their influencing factors. In short, research on the corresponding relationship between tool wear position and chip type in cutting process, which provides a theoretical basis for the breakage and adhesive prediction of tool in the cutting process.
\end{abstract}

Keywords: turning; tool wear; chip type

\section{Introduction}

In the metal cutting process, tool wear has important influence on chip patterns, chip shape and the force-thermal characteristics, particularly in the precision cutting process when metal removal amount is smaller. To a certain extent, tool wear determines the chip forming process. In recent years, with the machining precision requirements continuing to increase, precision machining causes widespread attention. Eiji Usui etc., whose theory is that the chips always flow out along the direction where cutting energy is least [1]. Jiang etc.,with multiple regression analysis method, on the test basis, establish a regression equation to estimate the flow crumbs angle [2]. Kharkevich A etc., make six kinds of definition that is used to describe the radius of upward curl and lateral curl [3].

Determine the parameters which control chip, in turn, it can express the size of the curl radius, this theory make a contribution to research the geometry shape of the chip. Iwata and Moriwaki established the steady rigid-plastic finite element model [4-5]. The model takes the impact of the tool edge radius into account, and studied the impact of cutting process from the interaction between the cutting thickness and the edge radius. Chen Yongjie etc., think that at the site of the cutting process, the tool groove wear and obstructions will generate constraints on the chip [6].

After tool were wore, the surface topography of the tool will change, which will lead to changes of the chip shape. This paper reveals the change rule and obtains the change trend of the flow direction and curl of the chip type before and after the tool were wore by analyzing the change trend of force process of chip wear state of cutting edge wear, groove wear and in the common minor cutting edge wear and the groove wear. All above lay the foundation for the research of the wear and breakage forecast of tool through the chip type change. 


\section{Cutting Experiment}

\subsection{Experiment Conditions}

The material of the workpiece is the Austenitic Stainless Steel ICrl8Ni9Ti, the specific chemical composition [7] are shown in the Table 1 and the diameter of the workpiece is $110 \mathrm{~mm}$. We choose carbide tool YT14 to do the turning experiment, as shown in Figure 1, Tool rake angle $\gamma=20^{\circ}$, relief angle $\alpha=0^{\circ}$, tool cutting edge angle $k_{r}=45^{\circ}$.

Table 1. Chemical Constituents of Stainless Steel 1Cr18Ni9Ti

\begin{tabular}{|c|c|c|c|c|c|c|c|c|}
\hline steel grade & \multicolumn{10}{|c|}{ lCrl8Ni9Ti } \\
\hline element & $\mathrm{C}$ & $\mathrm{Si}$ & $\mathrm{Mn}$ & $\mathrm{S}$ & $\mathrm{P}$ & $\mathrm{Cr}$ & $\mathrm{Ni}$ & $\mathrm{Ti}$ \\
\hline rated value & 0.058 & 0.41 & 1.2 & 0.014 & 0.039 & 17.16 & 8.04 & 0.28 \\
\hline
\end{tabular}

YT14 $16 \mathrm{~mm} \times 16 m \pi$

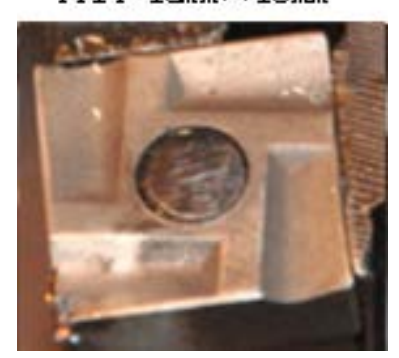

Figure 1. With Tool in the Experiment

We selected four typical sets of parameters about the tool wear from many sets of experimental parameters, which were shown as Table 2.

Table 2. Cutting Parameters

\begin{tabular}{|c|c|c|c|c|}
\hline level. factor & $a_{p}(\mathrm{~mm})$ & $n(\mathrm{r} / \mathrm{min})$ & $f(\mathrm{~mm} / \mathrm{r})$ & cutting time(s) \\
\hline 1 & 3 & 560 & 0.41 & 10 \\
\hline 2 & 3 & 710 & 0.41 & 7 \\
\hline 3 & 3 & 560 & 0.46 & 38 \\
\hline 4 & 3 & 710 & 0.41 & 15 \\
\hline
\end{tabular}

In the experimental process, in the Lathe Type CA6140, we measured the force in three different directions of the tool-holder with the Piezoelectric Dynamometer Type kistler92578 and recorded the cutting process with the high-speed photography (E-10). And the shooting frequency is $1000 \mathrm{~F} / \mathrm{s}$. The experimental cutting apparatus are shown in the Figure 2. 


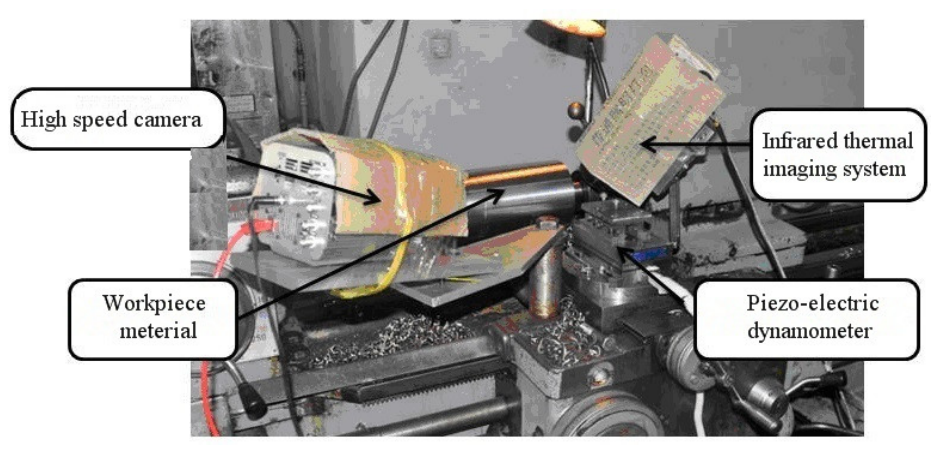

Figure 2. Experimental Cutting Apparatus

\section{Cutting Experiment Result Analysis}

\subsection{Relationship between Tool Wear Position and Chip Type}

In cutting process, with cutting condition being different, the tool wear may happen in the rake face, in the rear face, in the cutting edge, in the border or more points at the same time. With the production and the development of the wear, small changes are going to form between tool-workpiece so that the chips type changes [8].
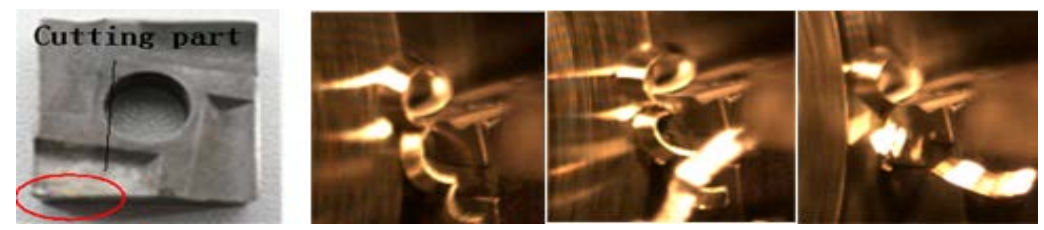

The tool and the chip type that the wear has not occurred

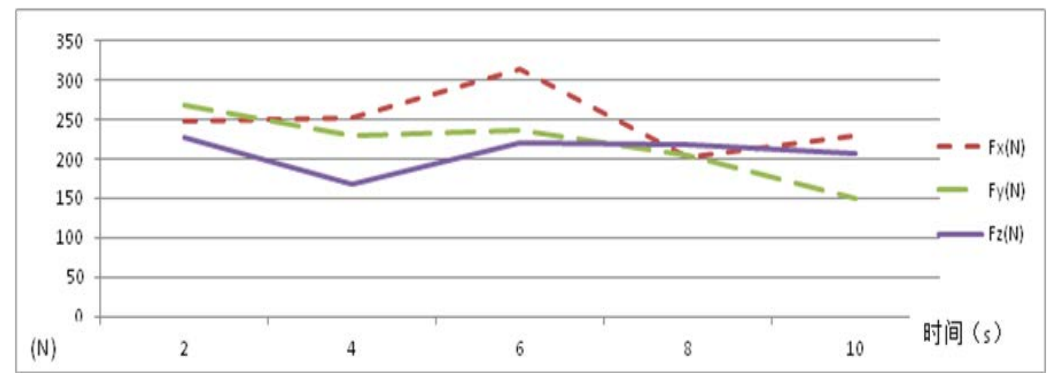

The cutting force values that the wear has not occurred

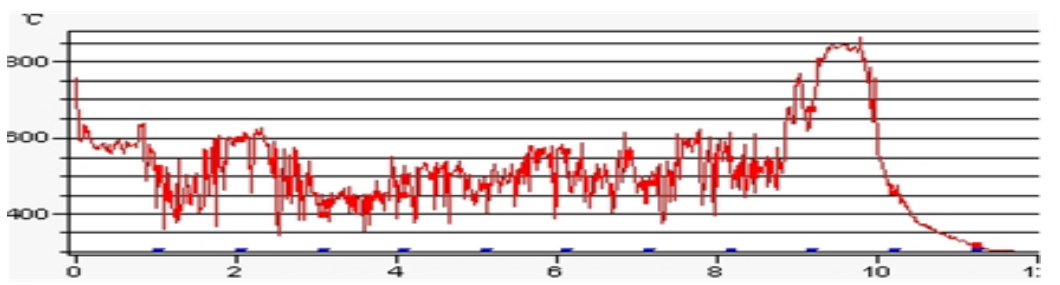

Cutting heat without tool wear

Figure 3. Histogram without Tool Wear 
With the first set of parameters, due to the cutting time is short, the tool didn't almost wear, Neither did the blade after cutting. With high-speed photography, we observed that the curly degree and curly way are same and the fluctuation of the cutting force measured by the dynamometer is very small. By removing those when starting cutting and ending cutting, namely a second area of the front and the rear, from the cutting heat data collected by Imager, we can draw that the cutting heat in the cutting process is stable at $450^{\circ}$, and with time goes on, the cutting heat is tend to slowly upward, as shown in Figure 3.
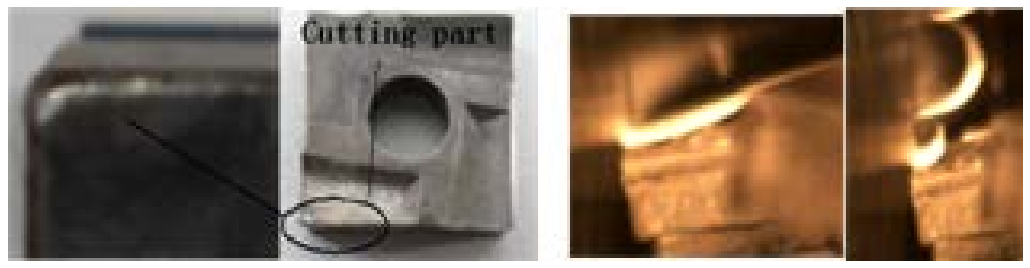

The tool and the chip type that the cutting edge wear has occurred

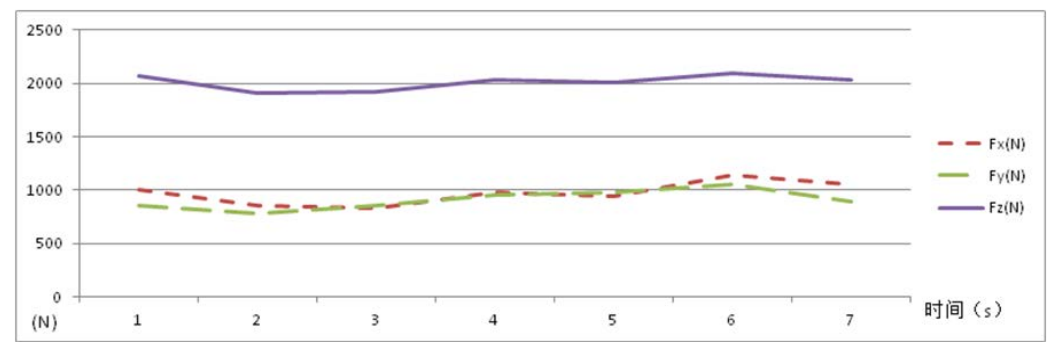

The cutting force values that the cutting edge wear has occurred

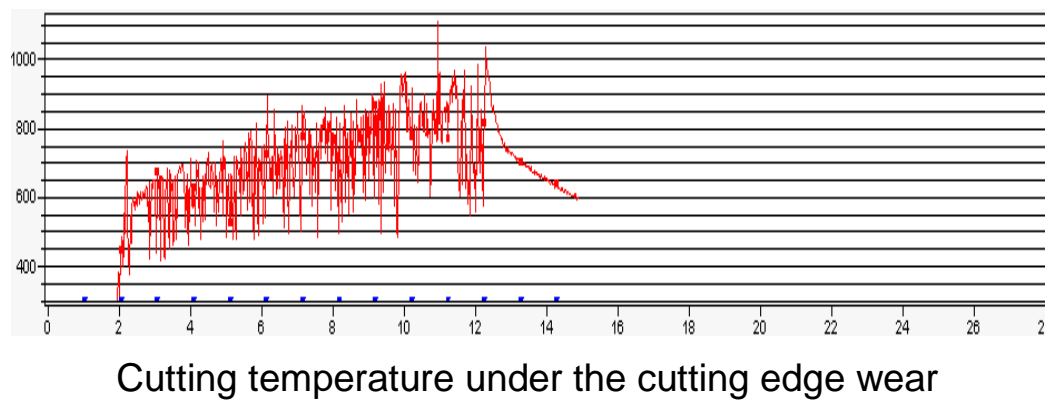

Figure 4. Histogram under Cutting Edges Wear

With the second set of parameters, the cutting edge of the blade turned dull and its wear situation is according with the wear state of the cutting edge. Through the visual diagram, we can see that the numerical value change of the force is not big, but the overall trend is increasing. In high-speed photography, we observed that the chip type was divided into two stages and its curly form and curly radius changed. the increasing trend of cutting heat value after the sixth second is obviously higher than that of a few seconds before, which is because that the wear generated at that time caused that coefficient of friction at the contact of tool and chip changed larger, frictions aggravated and the temperature value increased in the same cooling conditions. The above forces and thermal analysis shows that about the first 6 seconds after starting cutting, tool wear generates and the wear gradually increases as shown in Figure 4. 

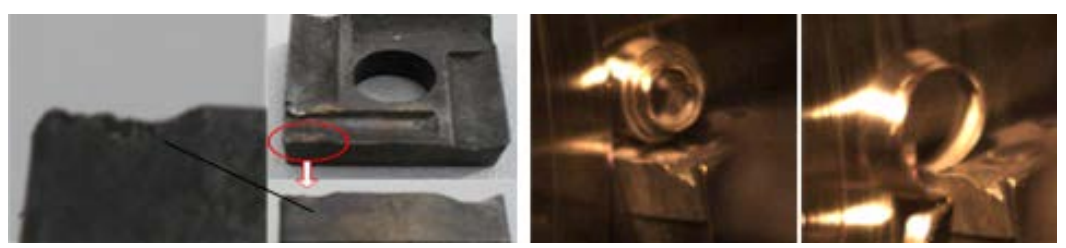

The tool and the chip type that the groove wear has occurred

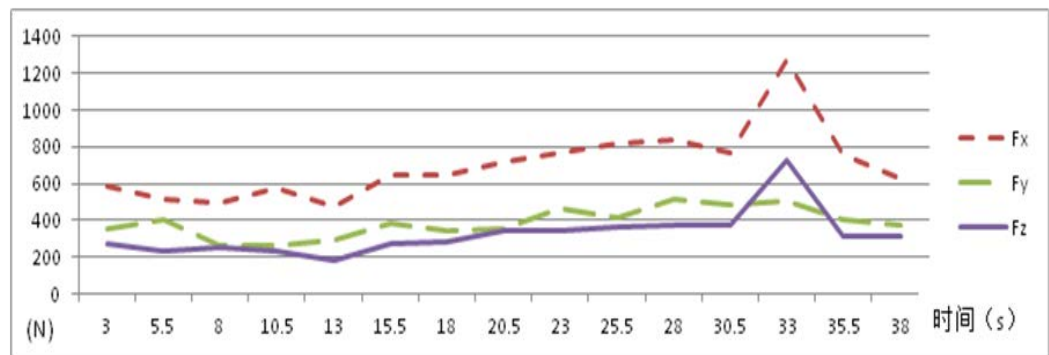

The cutting force values that the groove wear has occurred

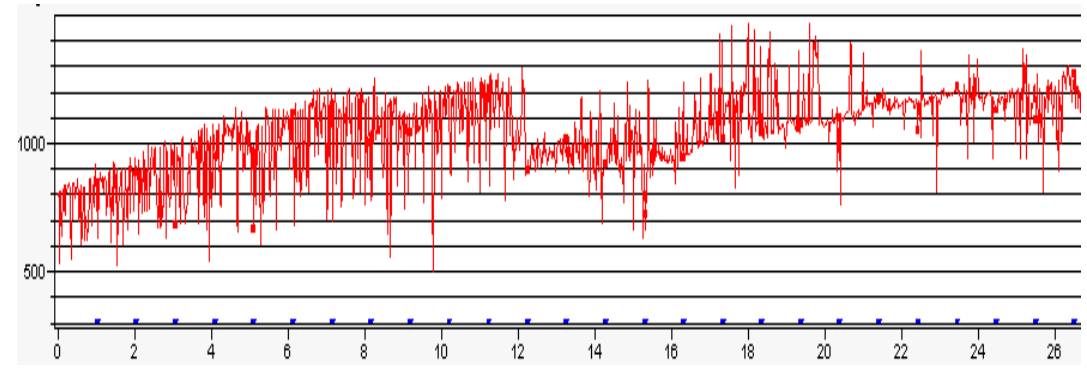

Cutting temperature under groove wear

Figure 5. Histogram under Groove Wear

With the third set of parameters, the main cutting edge of the blade appeared flawed. Chip type produced in the experiment become into light side-curl from the original upcurl. The value of the cutting force is gradually increasing. From Second 30 to Second 33 in the cutting process, there is a huge flop, which stage is also the boundary of two different chip types produced in the experiment. It is at this time that the violent wear occurred, which is corresponding with the groove wear condition. In the cutting process, at about the 15th second, the floating situation of cutting heat values were divided into two parts, which is due to that the wear generated at that time caused that coefficient of friction at the contact of tool and chip changed larger, frictions aggravated and the temperature value increased in the same cooling conditions.

The above forces and thermal analysis shows that about the first 15 seconds after starting cutting, tool wear generates and the wear gradually increases as shown in Figure 5.
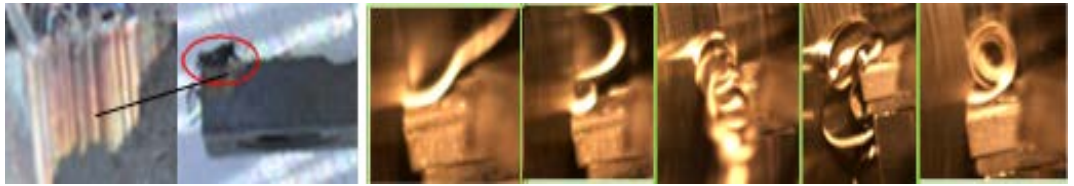

The tool and the chip type that the boundary wear has occurred 


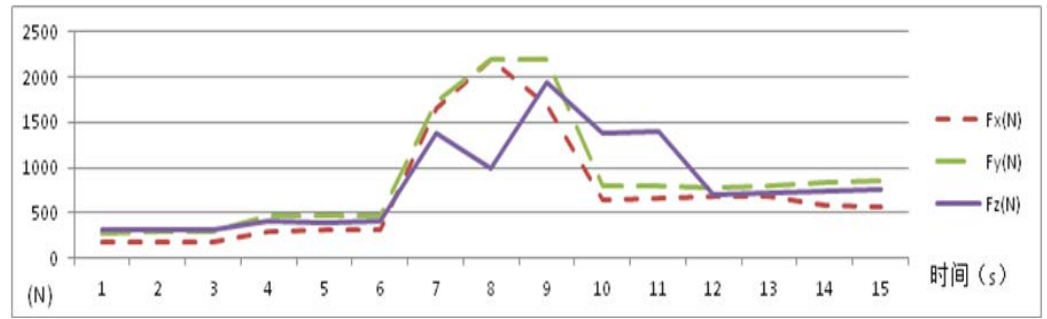

The cutting force values that the boundary wear has occurred

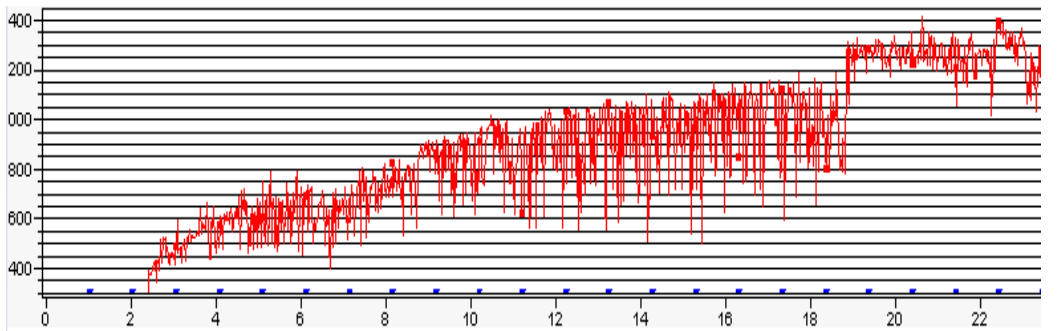

Cutting force changes when boundary worn occurred

Figure 6. Histogram when Boundary Worn Occurred

With the fourth set of cutting parameters, the wear condition of the blade is the same with the boundary wear after cutting. Through the visual diagram, we can see that the force change increased gradually from the initial stability, produced huge flop in the middle process, lasted a period of time and became stable too. This change process of numerical value is also according with the analysis results of the force in the boundary wear process. Through the high-speed photography, we observed that the chip type changed into up-curl with smaller radium from the one with larger radius, then there was the distortion with the side-curl trend, and then abnormal chips appeared, finally the chips was up-curl ones too. The change of chip type is also according with the analysis condition of the boundary wear. After the first 16 seconds, the cutting heat value gradually increases, which is due to that the wear generated at that time caused that coefficient of friction at the contact of tool and chip changed larger, frictions aggravated and the temperature value increased in the same cooling conditions.

From the above force and thermal analysis, we can know that after the 14th second when starting cutting, tool produces a worn, and in place between the 16th and the 21st seconds there is a dramatic tool wear as shown in Figure 6.

\subsection{Influence of the Cutting Edge Wear upon the Chip Type}

While cutting tool cut the workpiece material, the material is extruded into the side of processed surface by the flank, and left in the processed surface, and because of the elastic recovery, that part of the metal material will restore by the height of $\Delta \mathrm{h}$ in the reverse direction of the extruded material by the tool, the theoretical wear diagram is shown in Figure 7 (a), the actual tool wear is shown in Figure 7 (b). There are hardening and residual stresses on the machined surface after severe plastic deformation, where the metal of the surface acts on the tool flank, after the start of the cutting the flank will be worn away to form angle $\alpha_{o e}=0^{\circ}$, the edge named VB. 


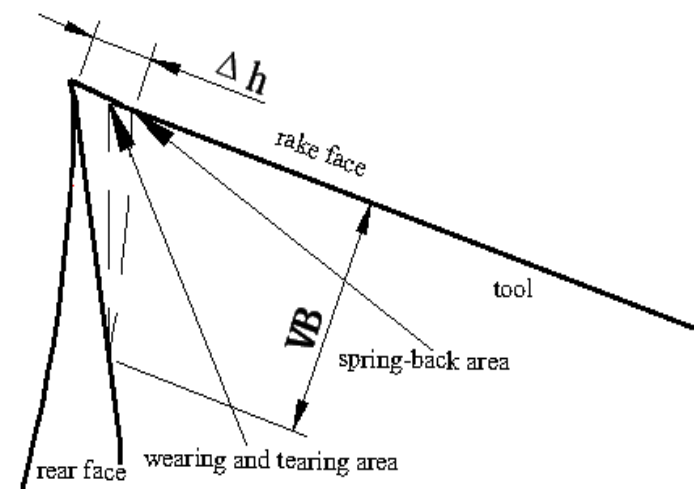

(a)

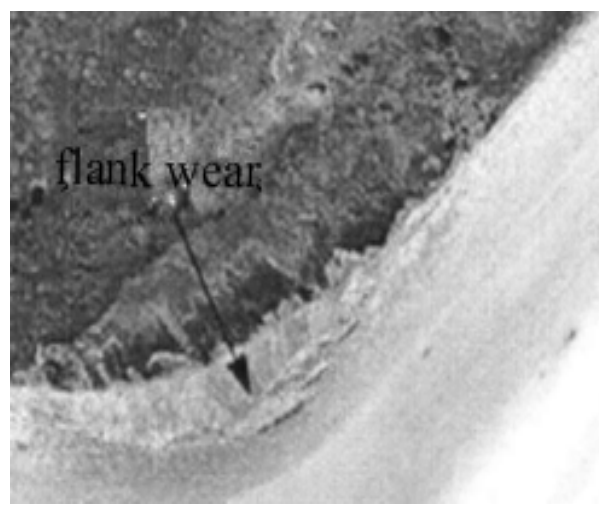

(b)

Figure 7. Flank Wear in Theory (a) and in Machining (b)

The wear value of tool is increased sharply at the start of cutting. Because of the stress concentration, the cutting edge rapidly wears. The parallel groove tool will change force direction of tool for chip after the cutting edge wore, as shown in Figure 8. $F_{1}, F_{2}$ are force conditions of chip before wear and the contact area of the tool and chip move backward after wear, then the $F_{1}$ changes into $F_{1}$ '. The changes of height at the tip of tool make $F_{2}$ change into $F_{2}$. The early wear only produces tiny changes on the tip of tool, but the value of the cutting force does not change in the process. So, in the process from the start of cutting to stabilize, the force direction changes curly degree of chip after flowing, which make the curly degree of the chip increase and curly radius of chip decrease.

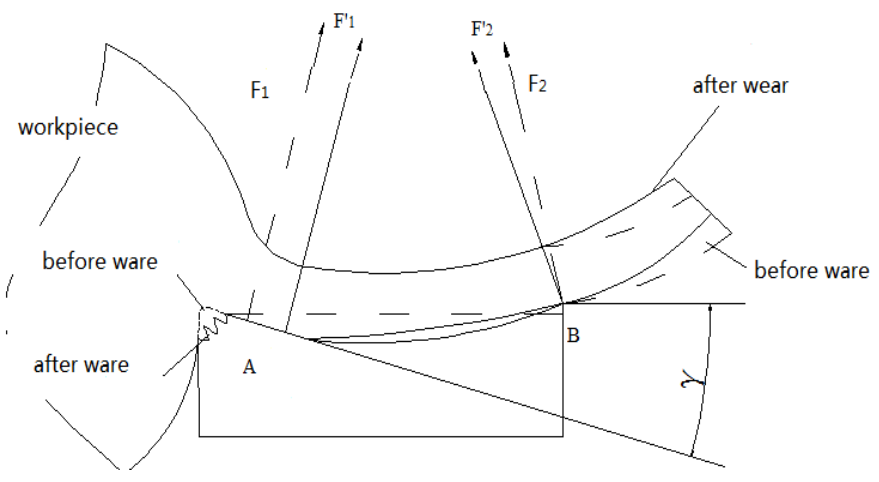

Figure 8. Changes of Chip before and after Wear

\subsection{Influence of the Groove Wear upon the Chip Type}

In turning excircle, the relative velocity between the outer boundary of the workpiece and the tool is maximum, where is prone to wear. In addition, processing the plastic metal, the workpiece material form the lateral plastic flow since the rake face and the tool nose extruded, which causes the sharp tip or burrs of the chip edge. Cutting the workpiece, the extrusion will lead to material lateral flow, the non-uniform flow make work surface form protruding tip or burr. The sharp chips tip constantly acting on the rake face and rear face of the tool edge, sharp tip constantly scratches or burrs high impact, which make the tool form the, with the continues wear, micro crack around 
expand and extend, forming groove wear[9-10], Figure 9 is groove wear in super depth of field microscopy.

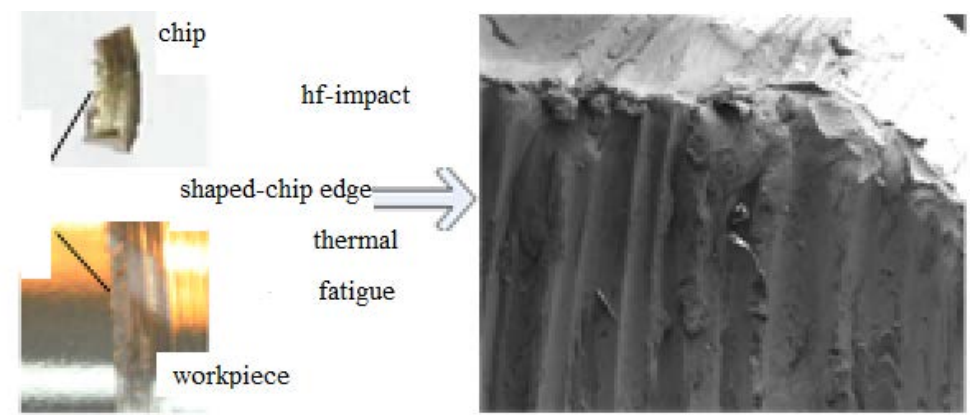

Figure 9. Forming Process of Groove Wear

The production, development and enlargement of groove wear will make the wear form of tool produce changes as shown in Figure 10. This kind of changes lead to form a similar positive cutting edge inclination between groove wear part $\mathrm{C}$ and cutting edge wear part $\mathrm{D}$, which made the cutting edge come into being angle change with the main movement direction [11]. Along with the increase of the wear degree, the angle change is also bigger and bigger and the force direction of chip changed as shown in Figure 11. Such changes cause the force of chip to become $F_{3}$ out of $F_{3}$ ', cause chip which flowed out appear side-curl trend. And its expression form is that the original upward curly chip will occur to transverse curl or distortion.

The intensifying of groove wear increases the contact area of chip and tool, also increases the friction coefficient of the tool surface, which will lead to the increase of the numerical value of the cutting force.
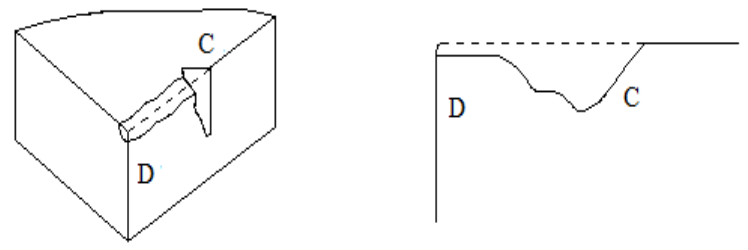

Figure 10. Schematic Diagram of Groove Wear State
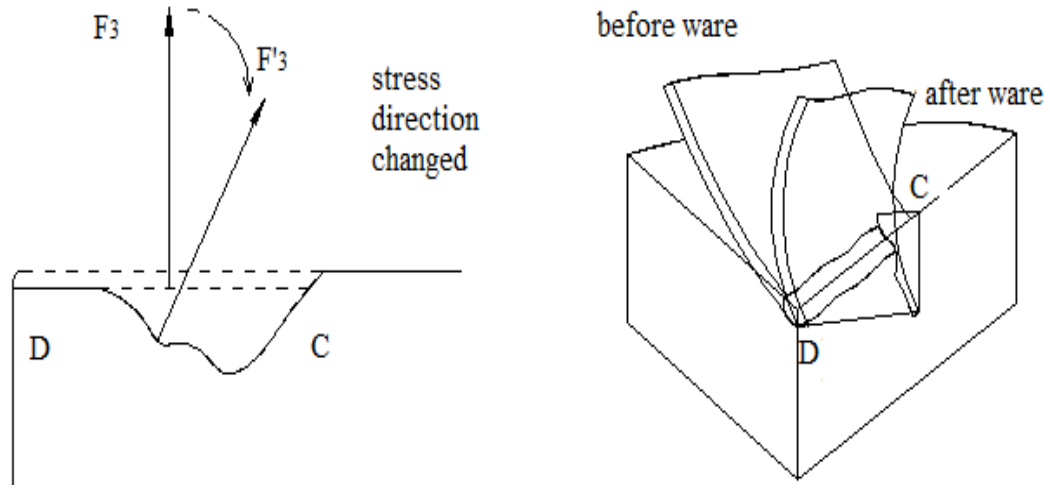

Figure 11. Schematic Diagram of the Influence of Groove Wear upon Chip 


\subsection{Influence of the Border Wear of the Minor Cutting Edge upon Chip Type}

In the actual cutting, the changed situation of generating tool nose wear and chip shape is shown in Figure 12, the surface of the wear is assumed to the uniform friction surface; boundary line which intersect between wear surface of the tool nose and the rake face, main rear face, side rear face is assumed to be continuous, $\mathrm{J}_{0} \mathrm{~J}_{0}{ }^{\prime}, \mathrm{J}_{0}{ }^{\prime} \mathrm{B}$ and $\mathrm{BJ}_{0}$ is express the boundary [12-13]. $\mathrm{J}_{0} \mathrm{~J}_{0}{ }^{\prime}$ is express the deepest tool nose wear with chord $\mathrm{J}_{0} \mathrm{~J}_{0}{ }^{\prime}$, the tool nose is express with $\mathrm{C}$, the junction border between the main cutting edge wear and non wear is represented by $B$, point $C$ to do over the tip chord $\mathrm{J}_{0} \mathrm{~J}_{0}$ ' of france plane AC chord $\mathrm{J}_{0} \mathrm{~J}_{0}{ }^{\prime}$ at point $\mathrm{B}$ ', the tool rake face and the flank angle of the wedge clip is represented by $1 / 2 \pi-\gamma, \eta^{3}$ deputy flank face chord CB 'and the chord $\mathrm{CJ}_{0}$ ' angle.

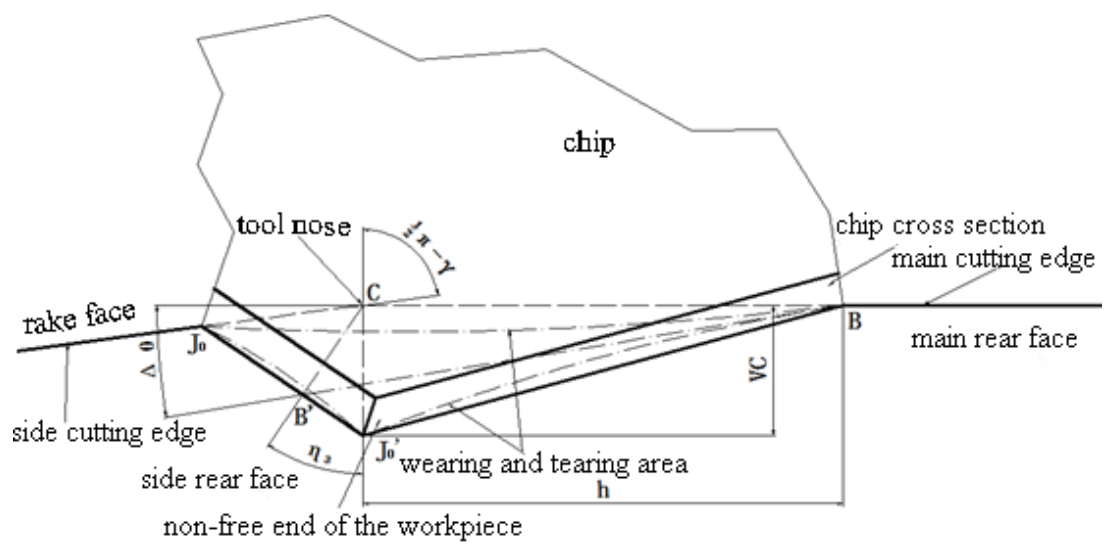

Figure 12. Tool Nose Wear Generated and Chips Changing

After mathematical derivation has the following relationship

$$
\tan \Delta \theta=\frac{C J_{0} \cdot V C \sin \left(\frac{1}{2} \pi-\gamma\right)}{J_{0} J_{0}^{\prime} h}
$$

In actual machin, at the straight line of the tool nose wear border can be measured, that $\mathrm{J}_{0} \mathrm{~J}_{0}{ }^{\prime}, \mathrm{VC}$ and $\mathrm{CJ}_{0}$ available, so the above equation is solvable. in the above formula relationship is satisfied, the maximum depth of the tool nose wear is less than feed, when occur in severe wear or damage in certain conditions, the maximum depth of the tool nose wear is greater than feed, in the case, the tool has the cutting function, the continues cutting process, in the deepest wear will only exist compression and no longer cut the workpiece, the width of the chips will be smaller. In the outward position, the wear form generated for the influence of chips shape, it can still be interpreted by the above described method.

\section{Conclusions}

1) By cutting experiments and theoretical analysis, it derives tool mainly wear position, that edge wear, tool nose wear and groove wear of the main cutting edge, the each location of the wear have established physical model, and draws chip type situation of the model. 
2) In the same cutting process, the tool occurs tool edge wear, tool nose wear $r$ and groove wear, it will produce the corresponding change for chip type, namely, tool edge wear makes the radius of the chip curl smaller; tool nose wear make the tool nose side less than the other side on chip width direction; groove wear makes the tool nose side away from the other side on chip width direction.

3) In the same cutting process, chip type changed, the tool generates the corresponding wear position. It demonstrated that chip type change is caused by the tool wear in different locations. Established correspondence relationship between tool wear and chip type.

\section{Acknowledgements}

This paper obtains the support of the national natural fund projects (51075109) \& Heilongjiang province ordinary college key laboratory open subject.

\section{References}

[1] E. Usui, “Cutting and grinding Processing”, Gao Xizheng interpreting. Beijing: Mechanical Industry Press, (1982).

[2] C. Y. Jiang, Y. Z. Zhang and Z. J. Chi, "Experimental, Research of the Chip Flow Direction and its Application to the Chip Control”, Annals of the CIRP., vol. 33, no. 1, (1984), pp. 81-84.

[3] A. Kharkebich and P. K. Venubinod, "Basic geometric analysis of 3-D chip forms in metal cutting”, Machine Tool\& Manufacture, vol. 39, (1999), pp. 751-769.

[4] K. Iwata, K. Osakada and Y. Terasaka, "Process modeling of orthogonal cutting by the rigid-plastic fininte element method”, Trans. ASMEJ. Eng. Mater. Technol, vol. 106, (1984), pp. 132-138.

[5] T. Moriwaki, N. Sugimura and S. Luan, “Arigid2plasticfinite elementanalysisof micro cutting”, Jpn. Soc. Precis. Eng, (1991), pp. 2163-2168.

[6] C. Yongjie and H. Weiwu, "Kinematics analysis of chip three-dimensional crimp", Chinese mechanical engineering, vol. 11, no. 5, (2000), pp. 513-515.

[7] L. Mei and G. Wei, "2.25Cr-1Mo-0.25V steel hydrogenation reactor”, Pressure vessel, vol. 20, no. 11, (2003), pp. 39-40.

[8] C. Hailei, J. Xiangang and T. Xiaobin, "Study on Chip Generating, Curling and Breaking”, East China Jiaotong University's Journal, (2002) February.

[9] X. Maohua, H. Ning and L. Liang, "Study on Saw-tooth-shaped Chip Edge and Tool Wear for High-speed Machining of Nickel-based Superalloy”, Tool Engineering, (2009) June.

[10] X. Maohua, H. Ning, L. Liang and L. Haibin, "Experimental Studies on Notch Wear for High Speed Machining of Nickel-based Superalloy with Ceramic Tools”, China Mechanical Engineering, (2008) October.

[11] L. Jiayi, "The Boundary Wear Increased and Suppression Method Caused by Shaped Chip Edge", Tool Engineering, (1987) May.

[12] L. Zhenjia, "Study on Chip Breaking Process”, Beijing: China Machine Press, (1996), pp. 13-17.

[13] C. Shunqing, “Chip flow direction influence on the chip”, Tool Technology, vol. 25, no. 4, (1991), pp. 38-40. 